\title{
Learning from the Lockdown: The Silver Linings of a Virtual Conference
}

Lydia R. Bailey, Samantha E. Portnoy, and Alexander B. Prescott*, Department of Geosciences, University of Arizona, Tucson, Arizona 85721, USA

\section{BACKGROUND}

Due to COVID-19, scientists and students alike moved from hallway discussions and group debates to working in isolation and participating in online classes. Academic and professional communities around the world have experienced significant cancellations of critical in-person events, including a number of scientific meetings. The University of Arizona Department of Geosciences 48th annual conference, GeoDaze, was no exception. GeoDaze was originally scheduled for April 2020, but all in-person university events were cancelled a few weeks prior. As organizers of the conference, we were initially devastated that we would not see all of our hard work come to fruition this year. Within a few days of the cancellation, our heartbreak transitioned to problem solving as we decided to redevelop the conference into an innovative virtual event. Surprisingly, there were several silver linings in the online conference that enhanced the event for attendees. As GeoDaze concluded, we wondered: What can we learn from the unprecedented pandemic lockdown to enhance scientific meeting experiences? Here we outline the benefits of transitioning a conference to an entirely virtual format, and we argue that some elements of online meetings are worth incorporating into a postCOVID-19 world.

GeoDaze is an annual university event inaugurated in 1972 that provides graduate and undergraduate students with the opportunity to present their latest geoscience research to the community. The entirely student-run conference draws in university alumni and geoscientists from industry, government, and academia. The ability for students to interact with professionals provides opportunities for career and academic growth through collaboration and guidance. This event often serves as the first opportunity for students to publicly present research, so there was a sense of urgency to maintain the annual tradition despite being met with initial hesitation and concern about moving GeoDaze to an entirely virtual format for the first time in history.

\section{VIRTUAL CONFERENCE FORMAT}

Considering that participants were uncertain about the new format, it was apparent that the website needed to be executed in a way that conveyed professionalism and reassured both participants and attendees that the virtual experience could be equally as effective as a traditional conference. In order to achieve this goal, we enlisted a GeoDaze committee member with a background in both geosciences and graphic design. This integration of multidisciplinary skills was a critical component lending to the success of the virtual conference. The culminating product, the GeoDaze 2020 website, was visually engaging and well organized (Fig. 1).

The site was built using SquareSpace, a website development platform, and CSS coding for customization. Conference attendees were able to easily navigate from the website home page, which served as a welcome platform with site navigation information and sponsor acknowledgments, to pages containing detailed conference information and scientific content. Traditional conference features, such as a welcome address, program, and conference schedule were available on the About page or in the linked Program, situated in the site navigation as a downloadable PDF. Although attendees could browse conference content at their own pace, the Program offered a suggested schedule to follow if the attendee wished to have a more traditional conference experience. In addition to these features, a conference Store was created to enable e-commerce transactions for conference merchandise, a key fundraising effort that normally takes place during traditional GeoDaze conferences.

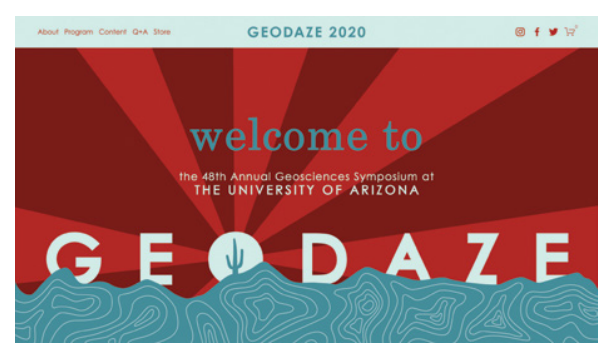

Figure 1. Formatting and design of the GeoDaze 2020 website home page.

Presentations were organized by type on two separate webpages, titled Posters and Talks. All talks and oral poster explanations were prerecorded using Panopto, an online video platform often used in e-learning environments for managing and recording lectures. Each poster or talk session was accompanied by a live one-hour question-and-answer session hosted through Video Webinars, a feature of the teleconferencing software, Zoom. These live forums were formatted so that attendees could pose questions for individual presenters during moderated time, followed by a general discussion. Live sessions were not recorded, and presentations were only available for the duration of the conference out of respect for unpublished research. To conclude the conference, an awards ceremony was held through Zoom, paralleling the traditional GeoDaze experience. Although unexpected, the virtual GeoDaze conference highlighted several benefits that align with the American Geosciences Institute objectives, components of which are easily integrable with future in-person conferences (American Geosciences Institute, 2015).

\section{ACCESSIBILITY}

One of the major takeaways from this experience is the impact the virtual conference format had on accessibility, which also lends to overall inclusivity. Panopto allows users to prerecord, manage, and edit their

GSA Today, v. 30, https://doi.org/10.1130/GSATG468GW.1. Copyright 2020, The Geological Society of America. CC-BY-NC.

*Corresponding author, alexprescott@email.arizona.edu. 


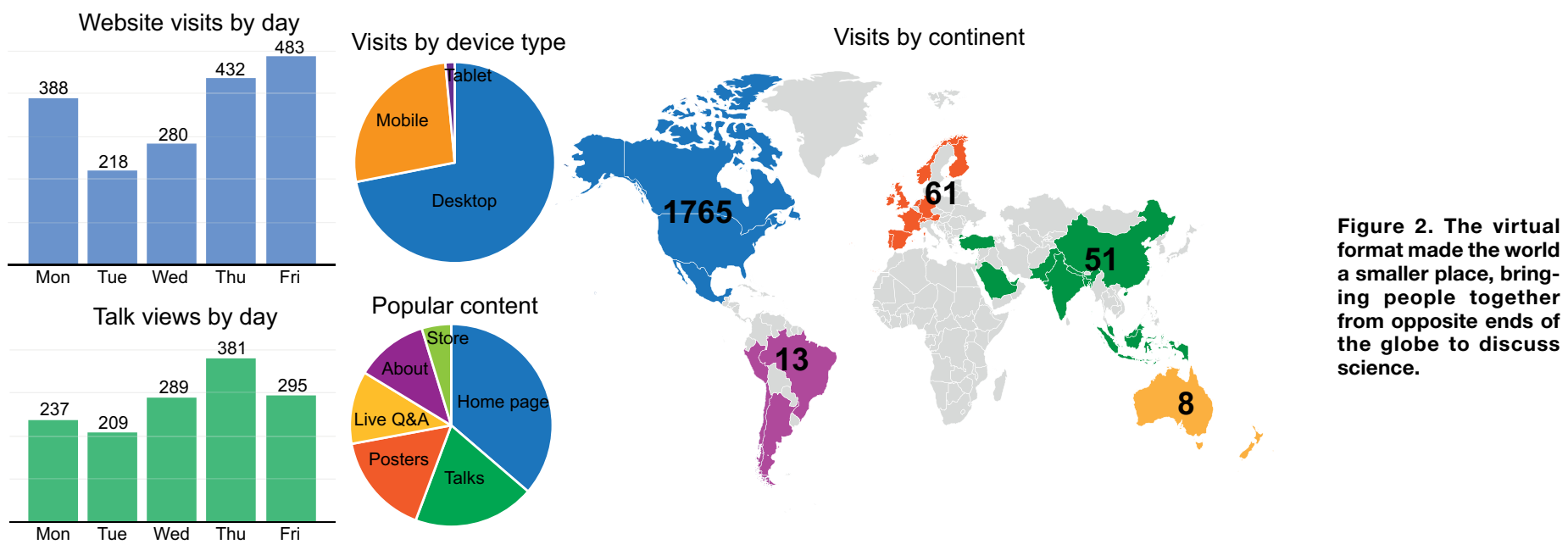

presentations, and recordings can be made available to a public audience or solely to those given access. The aspect of this technology that contributes the most to accessibility is the use of disability access features, such as video captioning and screen reader support, which enhance engagement of viewers with visual or auditory impairments. Many lines of evidence suggest that video captioning also improves retention of video content and viewer attentiveness for all (Gernsbacher, 2015). The additional function of variable speed playback can improve viewing for everyone, especially those with learning deficits, as it allows viewers to slow down or speed up recordings. These features, which were utilized during our virtual conference, are typically not available during in-person events, ultimately emphasizing the impact of virtually formatted scientific conferencing on accessibility.

\section{INCLUSIVITY}

The virtual format of GeoDaze made the conference available to people around the globe, compared to the normal in-person crowd of local attendees. Over the past five years, GeoDaze has averaged 130 registered attendees per year. This year the GeoDaze website had more than 1,300 unique visitors (a statistical count of non-repetitive website viewers). The Talks and Posters pages had more than 800 and 700 unique visitors, respectively. Website statistics recorded visitors from five continents (Fig. 2), providing for a much more geographically diverse audience than those of prior conferences. Additionally, website organization, formatting, and design all made it possible for people to access the conference on any device, which was ultimately beneficial considering that $27 \%$ of attendees tuned in on their mobile devices. Students and early career professionals often lack the financial resources to attend conferences, which can inhibit career and academic advancement, but virtual formatting alleviates this issue.

Under the traditional conference format, attendees must adhere to the conference schedule in order to participate. The virtual format allowed for asynchronous viewing of presentations; attendees were able to access and view prerecorded presentations at their own convenience and pace during the week that the website was live. This flexibility led to noticeably increased engagement during interactive sessions, likely because viewers could rewatch particularly complex presentations, improving comprehension, and they had time to postulate questions for the presenters. The use of a video conferencing platform gave attendees the option to ask questions vocally or to type questions in the Chat or $Q \& A$ software features. In our experience, this provided an environment that encouraged questions from all participants, including those who would normally feel too intimidated or embarrassed to ask in person. Although virtual interactions may not provide the same social gratification as face-to-face conversations, we found that the virtual $Q \& A$ sessions provoked interesting, and sometimes extensive, discussions that the traditional three-minute post-talk timeframe sometimes fails to encourage. On top of all of the aforementioned benefits for inclusivity, virtual conference formatting also addresses the growing concern for scientific meetings to reduce their carbon footprint.

\section{FUTURE INTEGRATION}

GeoDaze was one of many events around the globe that was disrupted by COVID-19. The goal of this piece was to highlight the fortuitous silver linings that came out of our means of adapting to the circumstances by developing a virtual conference. Given the positive takeaways outlined here, we believe that future in-person conferences could benefit from incorporating elements of virtual conferences, like ours, into the traditional format. With this suggestion, consider these key takeaways:

1. Virtual recording software, such as Panopto, offers disability features that increase accessibility for both presenters and viewers, an option that often does not exist for traditional conferences.

2 . The asynchronous and virtual viewing format of our conference encouraged geographic viewer diversity, indicating that this format allows for increased accessibility and inclusivity.

3. The combination of accessibility features and self-paced conference attendance allows for better comprehension of scientific information, which can stimulate engagement during live session discussions, ultimately leading to increased scientific advancement.

4. This virtual conference serves as an example of how integrative collaboration of visual arts and science can produce innovative means for conveying scientific information that are highly effective due to the effects of enhanced visual literacy.

\section{REFERENCES CITED}

American Geosciences Institute, 2015, Disability Consensus Statement: https://www.american geosciences.org/community/disability-consensus -statement (accessed May 2020).

Gernsbacher, M.A., 2015, Video captions benefit everyone: Policy Insights from the Behavioral and Brain Sciences, v. 2, p. 195-202, https://doi.org/ $10.1177 / 2372732215602130$.

MANUSCRIPT RECEIVED 4 June 2020

REVISED MANUSCRIPT RECEIVED 8 JuLy 2020

MANusCRIPT ACCEPTED 12 July 2020 